\title{
Safety of Intraoperative Transcranial Electrical Stimulation Motor Evoked Potential Monitoring
}

\author{
David B. MacDonald \\ Section of Clinical Neurophysiology, Department of Neurosciences, King Faisal Specialist Hospital \& Research Center, Riyadh, \\ Saudi Arabia
}

\begin{abstract}
Summary: This article reviews intraoperative transcranial electrical stimulation (TES) motor evoked potential (MEP) monitoring safety based on comparison with other clinical and experimental brain stimulation methods and clinical experience in more than 15,000 cases. Comparative analysis indicates that brain damage and kindling are highly unlikely. There have been remarkably few adverse events. Pulse train TESinduced or coincidental seizures $(n=5)$ are rare, probably because of very brief $(<0.03$ second $)$ stimuli, anesthesia, and the general absence of predisposing cerebral conditions. Soft bite blocks may prevent tongue or lip laceration $(\mathrm{n}=29)$ or mandibular fracture $(n=1)$. Rare cardiac arrhythmia $(n=5)$ and intraoperative awareness $(n=1)$ may be coincidental. Minor scalp burns $(n=2)$ are rare. Although possible, no spinal epidural recording electrode complications or injuries resulting from TES-induced movement were found. There have been no recognized adverse neuropsychological effects, headaches, or endocrine disturbances. Comprehensive relative contraindications include epilepsy, cortical lesions, convexity skull defects, raised intracranial pressure, cardiac disease, proconvulsant medications or anesthetics, intracranial electrodes, vascular clips or shunts, and cardiac pacemakers or other implanted biomedical devices. Otherwise unexplained intraoperative seizures and possibly arrhythmias are indications to abort TES. With appropriate precautions in expert hands, the well-established benefits of TES MEP monitoring decidedly outweigh the associated risks. Key Words: Intraoperative monitoring-Transcranial electrical stimulation-Motor evoked potentials-Adverse effects-Safety.
\end{abstract}

Transcranial electrical stimulation (TES) motor evoked potential (MEP) monitoring involves repetitive brain stimulation and spinal epidural recording electrodes or patient movement, raising safety concerns. Based on comparison with other cerebral stimulation methods and a review of published reports and unpublished experience, this article assesses TES MEP monitoring risks within the context of its benefits.

Address correspondence and reprint requests to Dr. David B. MacDonald, Section of Clinical Neurophysiology, Department of Neurosciences, King Faisal Specialist Hospital \& Research Center, MBC 76, PO Box 3354, 11211 Riyadh, Saudi Arabia; e-mail: dbmacdon@ yahoo.com.

\section{BENEFITS OF TRANSCRANIAL ELECTRICAL STIMULATION MOTOR EVOKED POTENTIAL MONITORING}

Paralysis complicating surgery causes enormous suffering and costs. Monitoring may prevent this by identifying reversible neurologic compromise (American Academy of Neurology, 1990; Nuwer et al., 1995). However, motor compromise can occur without sensory evoked potential warning (Ben-David et al., 1987; Dawson et al., 1991; Lesser et al., 1986; Nuwer et al., 1995; MacDonald and Janusz, 2002; Meylaerts et al., 1999), and sensory evoked potential deterioration can occur without motor deficits (Calancie et al., 2001; Dawson et al., 1991; Forbes et al., 1991; Kothbauer et al., 1997; 
Nuwer et al., 1995). Thus, specific MEP methods are needed.

Spinal cord stimulation activates motor tracts but also produces antidromic sensory potentials and lower motor neuron excitation through Ia afferent segmental synapses (Deletis, 1993; Rose, 1996; Su et al., 1992). Therefore, even muscle responses cannot be attributed to motor tracts alone. Some reports suggest that mixed peripheral nerve potentials after cord stimulation provide MEPs attributable to motor tracts (Owen et al., 1988). Others indicate a predominantly sensory content (Leppanen et al., 1999; Toleikis et al., 2000). Spinal-elicited neurogenic responses can be recorded from the purely sensory sural nerve (Delecrin et al., 2000), and have missed motor deficits in experimental animals (Kai et al., 1994) and paraplegia during scoliosis surgery (Minahan et al., 2001).

Transcranial electrical stimulation or transcranial magnetic stimulation (TMS) activates corticofugal motor pathways without antidromic sensory contamination (Barker et al., 1987; Merton and Morton, 1980). Transcranial electrical stimulation is practical and may be more effective intraoperatively (Thompson et al., 1991; Ubags et al., 1999). Single pulses produce a corticospinal "D wave" from direct cortical neuron axonal depolarization that can be recorded in the spinal epidural space and can be used to monitor motor tract integrity, but usually fails to depolarize lower motor neurons (Boyd et al., 1986; Burke et al., 1992; Deletis, 1993). Fig. 1 illustrates very brief, high-frequency pulse train ("multiple pulse") TES producing muscle responses through temporal summation of several corticospinal volleys to depolarize spinal motor neurons (Jones et al., 1996; Pechstein et al., 1996; Rodi et al., 1996). Myogenic MEPs may be more sensitive to cord ischemia because alpha motor neurons are more rapidly disabled by ischemia than tracts (de Haan et al., 1996; MacDonald and Janusz, 2002). They may also detect unilateral motor pathway compromise that could be missed by monitoring the spinal "D wave" alone. Both methods have been shown to be valuable for specific motor deficit detection and prevention (Calancie et al., 1998, 2001; Cioni et al., 1999; de Haan et al., 1998; Deletis and Sala, 2001; Jacobs et al., 2000; Jones et al., 1996; Kothbauer et al., 1997, 1998; MacDonald and Janusz, 2002; MacDonald et al., 2001; Meylaerts et al., 1999; Morota et al., 1997; Sala et al., 2001).

\section{SAFETY CONCERNS}

Safety concerns include the possibilities of brain damage, seizures, kindling, epidural complications, accidental injury resulting from patient movement, bite injuries, adverse cognitive or affective sequelae, and other complications such as cardiac arrhythmia, intraoperative

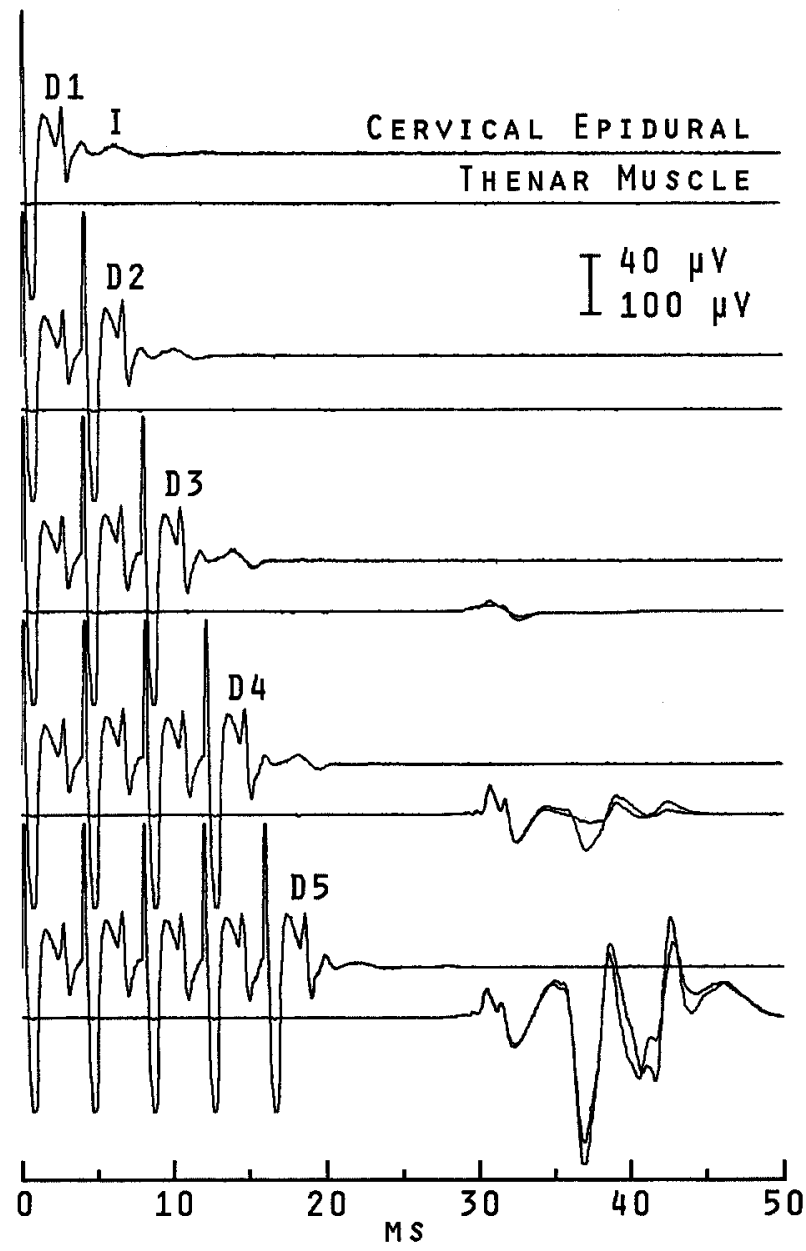

FIG. 1. Transcranial electrical stimulation epidural and muscle responses during $\mathrm{C} 2$ to 3 meningioma surgery under propofol and fentanyl anesthesia omitting neuromuscular blockade. Epidural recording (bandwidth, 500 to $10,000 \mathrm{~Hz}$ ) used a bipolar electrode inserted caudal to the lesion after opening. Muscle recording (bandwidth, 20 to $3,000 \mathrm{~Hz}$ ) used intramuscular needle pairs. Traces consist of two superimposed averages of five trials. D1 through D5 are sequential D wave corticospinal volleys following one through five pulses (Nicolet Viking, 0.5-msec pulse duration, 250-Hz train frequency, $250 \mathrm{~V}$ ) through 9-mm cup electrodes collodion fixed $1 \mathrm{~cm}$ anterior to $\mathrm{C} 1 / 2$. A small I wave follows each. Temporal summation produced progressive motor unit recruitment with three through five-pulse trains. The brain stimulation, epidural electrode, and induced movement raise safety concerns discussed in this article. Single-pulse epidural and five-pulse train muscle motor evoked potential monitoring was successful without adverse effects in this patient.

awareness, scalp burns, pain or headache, and disturbances of hormonal or hematologic homeostasis. An assessment of these potential risks must compare TES with other clinical and experimental methods considering stimulus parameters, published results, and unpublished clinical experience. 


\section{Parameters of Electrical Stimulation}

Electrical stimulation is bipolar-between a positive anode and a negative cathode. One pulse may be monophasic, or biphasic when there is second phase of equal duration (duration or D is measured in milliseconds) but opposite polarity. Stimuli are rectangular, sinusoidal, or decay exponentially (capacitor discharge) according to $\mathrm{I}_{\mathrm{t}}=\mathrm{I} \times e^{-\mathrm{t} / \mathrm{TC}}$ where $\mathrm{I}_{\mathrm{t}}$ is the current in milliamps at time $t$, $I$ is the peak current, and TC is a time constant at which $\mathrm{I}_{\mathrm{t}}$ falls to $\mathrm{I} \times 1 / e$. Charge $(\mathrm{Q})$ in microcoulombs per phase $(\mu \mathrm{C} / \mathrm{ph})$ is defined as $\mathrm{I} \times \mathrm{D}$ for rectangular pulses, $0.637 \times \mathrm{I} \times \mathrm{D}$ for sine waves, and I $\times$ TC for exponentially decaying pulses. Charge density (QD) in microcoulombs per square centimeter per phase is defined as $\mathrm{Q} \times$ electrode geometric area $(\mathrm{A}$, in square centimeters), and decreases rapidly according to the square of the distance and the resistance of tissues between the electrodes and the neural target. Pulse trains are repetitive pulses of a selected frequency (f, in Hertz) and duration or time in seconds. Total charge $\left(Q_{t}\right)$ and total charge density $\left(\mathrm{QD}_{\mathrm{t}}\right)$ are defined as $\mathrm{Q}$ or $\mathrm{QD}$ times the number of phases $(2 \times$ the pulse number for biphasic stimuli) in a pulse train.

Voltage $(\mathrm{V})=\mathrm{I} \times \mathrm{R}$, where $\mathrm{R}$ is the resistance in Ohms. Energy in Joules $=\mathrm{V} \times \mathrm{Q}$ and produces heat. Constant voltage stimulators adjust the current to maintain voltage; constant current stimulators adjust the voltage to maintain current.

Several stimulators are used currently for TES MEP monitoring. The constant-voltage D185 and D180A use 0.05 -msec rectangular pulses and 0.05 or 0.1 -msec time constants respectively (Digitimer Ltd., Welwyn Garden City, UK). These brief monophasic pulses reduce scalp discomfort (Merton and Morton, 1980) but require higher intensity than longer pulses to produce a similar charge. The D180A generates single pulses at less than $0.5 \mathrm{~Hz}$. The D185 generates trains of one to nine pulses (maximum, three pulses at highest intensity) with a frequency of 101 to $1,000 \mathrm{~Hz}$ (interstimulus interval, 9.9 to $1 \mathrm{msec}$ ) and measures delivered current. More than 300 D185 stimulators are in use in more than 25 countries, and this device is approved in Europe, Japan, and recently in the United States (Benedict, HJ, Digitimer Ltd., personal communication). Kothbauer et al. (1997, 1998) and Deletis et al. (2001a, b) reported a custommade constant current stimulator using up to $0.5-\mathrm{msec}$ rectangular monophasic pulses which enhanced $\mathrm{D}$ wave recovery time compared to shorter pulses. Bartley et al. (2002) examined 0.05 to 1 -ms pulses and found that the threshold charge to elicit MEPs increased with longer pulse widths but pointed out that this does not imply that longer pulses are less safe. Other stimulators can be effective using 0.5 -msec monophasic pulses, such as the Viking (Nicolet Biomedical Inc., Madison, Wisconsin, USA). Although limited to $100 \mathrm{~mA}$ in constant current mode, current could approach $200 \mathrm{~mA}$ at the $400-\mathrm{V}$ maximum constant voltage setting (unpublished data) and can approach 500 to $750 \mathrm{Ohm}$ resistance during TES as reported by Calancie et al. (1998). Table 1 (Deletis et al., 2001a, b; Gordon et al., 1993; McCreery et al., 1990; Levy et al., 1994; Stephens et al., 1991; Taniguchi et al, 1993a; Wada et al., 1978; Yuen et al., 1981) compares maximum intensity of these stimulators to other brain stimulation methods. Calculations are based on 9-mm cup stimulating electrodes, five-pulse (three-pulse for the D185) 250-Hz trains (Deletis et al., 2001a, b), and averages 10 trials for epidural MEP (using the D180A).

\section{Neuronal Damage}

Excitotoxicity is considered the major neuronal injury mechanism (McCreery et al., 1988, 1990; Pudenz et al., 1975, 1977; Yuen et al., 1981). Toxic electrochemical and electrolytic reactions at the electrode-tissue interface during direct (but not transcranial) stimulation are avoided partially by biphasic pulses (Agnew and McCreery, 1987; Girvin, 1978; Gordon et al., 1990). Tissue heating is negligible in the forms of stimulation discussed in this article (Wasserman, 1998; Yuen et al., 1981).

Based on histology after prolonged, continuous $50-\mathrm{Hz}$ biphasic rectangular pulse direct cortical stimulation in cats, charge density and charge per phase are excitotoxic cofactors such that higher charge density can be tolerated with lower charge per phase and visa versa (McCreery et al., 1990; Yuen et al., 1981). Increasing total charge and total charge density augments severity (Agnew and McCreery, 1987). Damage has been limited to neurons immediately adjacent to stimulating electrodes.

Yuen et al. (1981) identified an injury threshold of 40 $\mu \mathrm{C} / \mathrm{cm}^{2} \cdot$ ph at $0.4 \mu \mathrm{C} / \mathrm{ph}$ when administered in $50-\mathrm{Hz}$ biphasic pulse trains for 15 hours (see Table 1, Exp.1). Although intended to evaluate chronic direct stimulation, this has been used to judge TES safety (Agnew and McCreery, 1987). Subsequently, McCreery et al. (1990) showed that 7 hours of $50-\mathrm{Hz}$ biphasic stimulation at 10 $\mu \mathrm{C} / \mathrm{cm}^{2} \cdot$ ph and $5 \mu \mathrm{C} / \mathrm{ph}$ was noninjurious whereas 12 $\mu \mathrm{C} / \mathrm{cm}^{2} \cdot$ ph at $6 \mu \mathrm{C} / \mathrm{ph}$ produced mild damage at some sites (see Table 1, Exp.2). The effect of shorter pulse trains has not been explored by these experiments.

In humans, Gordon et al. (1993) found no histologic damage after $50-\mathrm{Hz}$ biphasic pulse train subdural grid stimulation (3.175-mm disks) at as much as $57 \mu \mathrm{C} / \mathrm{cm}^{2}$ 
TABLE 1. Comparison between some clinical and experimental brain stimulation methods

\begin{tabular}{|c|c|c|c|c|c|c|c|c|c|c|c|c|c|}
\hline \multirow[b]{3}{*}{ Variable } & \multicolumn{7}{|c|}{ Transcranial stimulation } & \multicolumn{6}{|c|}{ Direct cortical stimulation } \\
\hline & \multicolumn{4}{|c|}{ TES MEP } & \multirow[b]{2}{*}{ ECT } & \multirow[b]{2}{*}{ TMS } & \multirow[b]{2}{*}{ rTMS } & \multirow[b]{2}{*}{$\mathrm{cMEP}$} & \multirow[b]{2}{*}{ Grid } & \multirow[b]{2}{*}{ Probe } & \multirow[b]{2}{*}{ Kindle } & \multirow[b]{2}{*}{ Exp. 1} & \multirow[b]{2}{*}{ Exp. 2} \\
\hline & D185 & Deletis & Viking & D180A & & & & & & & & & \\
\hline $\mathrm{I}, \mathrm{mA}$ & 1,500 & 240 & 200 & 1,500 & 1,000 & $2.5 \mathrm{~T}$ & $2.5 \mathrm{~T}$ & 20 & 15 & 4 & 0.5 & 4 & 15 \\
\hline $\mathrm{D}, \mathrm{ms}$ & 0.05 & 0.5 & 0.5 & $0.1^{*}$ & 1 & 0.6 & 0.6 & 0.5 & 0.3 & 1.25 & $8.3^{\dagger}$ & 0.1 & 0.4 \\
\hline $\mathrm{A}, \mathrm{cm}^{2}$ & 0.64 & 0.64 & 0.64 & 0.64 & 13 & - & - & 1 & 0.08 & 0.02 & 0.006 & 0.01 & 0.5 \\
\hline $\mathrm{f}, \mathrm{Hz}$ & 250 & 250 & 250 & 0.4 & 60 & - & 25 & 500 & 50 & 50 & 60 & 50 & 50 \\
\hline Time, sec & 0.01 & 0.02 & 0.02 & 25 & 5 & $6 E-4$ & 10 & 0.01 & 5 & 5 & 1 & $54 \mathrm{E}+3$ & $25 E+3$ \\
\hline Phases & 3 & 5 & 5 & 10 & 300 & 1 & 250 & 5 & 500 & 500 & 120 & $54 \mathrm{E}+5$ & $25 \mathrm{E}+5$ \\
\hline Scalp Q, $\mu \mathrm{C} / \mathrm{ph}$ & 75 & 120 & 100 & 150 & 1,000 & - & - & - & - & - & - & - & - \\
\hline $\mathrm{QD}, \mu \mathrm{C} / \mathrm{cm}^{2} \cdot \mathrm{ph}$ & 118 & 189 & 157 & 236 & 77 & - & - & - & - & - & - & - & - \\
\hline $\mathrm{Qt}, \mu \mathrm{C}$ & 225 & 600 & 500 & 1,500 & $30 \mathrm{E}+4$ & - & - & - & - & - & - & - & - \\
\hline Brain $\mathrm{Q}, \mu \mathrm{C} / \mathrm{ph}$ & 3.8 & 6.0 & 5.0 & 7.5 & 50 & - & - & 10 & 4.5 & 5.0 & 2.7 & 0.4 & 6.0 \\
\hline $\mathrm{QD}, \mu \mathrm{C} / \mathrm{cm}^{2} \cdot \mathrm{ph}$ & 5.9 & 9.4 & 7.9 & 11.8 & 3.8 & 3 & 3 & 10 & 57 & 318 & 424 & 40 & 12 \\
\hline $\mathrm{Qt}, \mu \mathrm{C}$ & 11 & 30 & 25 & 75 & $15 E+3$ & - & - & 50 & 2,250 & 2,500 & 318 & $22 \mathrm{E}+5$ & $15 E+6$ \\
\hline QDt, $\mu \mathrm{C} / \mathrm{cm}^{2}$ & 18 & 47 & 39 & 118 & 1,154 & 3 & 750 & 50 & $28 \mathrm{E}+3$ & $16 \mathrm{E}+4$ & $51 \mathrm{E}+3$ & $22 \mathrm{E}+7$ & $30 \mathrm{E}+6$ \\
\hline Neural damage & $\mathrm{N}$ & $\mathrm{N}$ & $\mathrm{N}$ & $\mathrm{N}$ & $\mathrm{N}$ & $\mathrm{N}$ & $\mathrm{N}$ & $\mathrm{N}$ & $\mathrm{N}$ & $\mathrm{N}$ & $\mathrm{N}$ & $\mathrm{Y}$ & $\mathrm{Y}$ \\
\hline Seizures & Rare & Rare & Rare & $\mathrm{N}$ & $\mathrm{Y}$ & Rare & $\mathrm{Y}$ & Rare & $\mathrm{Y}$ & $\mathrm{Y}$ & $\mathrm{Y}$ & $\mathrm{Y}$ & - \\
\hline Kindling & $\mathrm{N}$ & $\mathrm{N}$ & $\mathrm{N}$ & $\mathrm{N}$ & $\mathrm{N}$ & $\mathrm{N}$ & $\mathrm{N}$ & $\mathrm{N}$ & $\mathrm{N}$ & $\mathrm{N}$ & $\mathrm{Y}$ & - & - \\
\hline Cognitive/mood & $\mathrm{N}$ & $\mathrm{N}$ & $\mathrm{N}$ & $\mathrm{N}$ & Y & $\mathrm{N}$ & Y? & $\mathrm{N}$ & $\mathrm{N}$ & $\mathrm{N}$ & - & - & - \\
\hline
\end{tabular}

TES MEP, transcranial electric stimulation motor evoked potentials; D185 and D180A (Digitimer Ltd., Welwyn Garden City, UK); Deletis, custom-made stimulator (Deletis et al., 2001 a, b); Viking, Nicolet Biomedical Inc., Madison, Wisconsin, USA; ECT, electroconvulsive therapy, parameters from Stephens et al. (1991); TMS, transcranial magnetic stimulation; rTMS, repetitive TMS; cMEP, direct cortical stimulation for MEPs (Taniguchi et al., 1993a); Grid, Probe, traditional subdural grid and hand-held probe cortical stimulation (Gordon et al., 1990); Kindle, Rhesus monkey kindling (Wada et al., 1978); Exp. 1 and Exp. 2, injury threshold levels in feline prolonged stimulation experiments (McCreery et al., 1990; Yuen et al., 1981); T, Tesla; *time constant; ' ${ }^{\prime}$ sine wave; Q, charge per phase; QD, charge density; Qt, total charge; QDt, total charge density; N, no or not reported; Y, yes. Estimated TES brain charges are based on a scalp-to-brain dispersion factor of 1:20. Actual charges may be less if the 1:30 dispersion proposed by Levy et al. (1984) is more correct. The rare occurrence of seizures with TES MEPs or cMEPs is based on unpublished observations.

$\times$ ph and $4.5 \mu \mathrm{C} / \mathrm{ph}$ (see Table 1, Grid). Cortical stimulation with hand-held probes (see Table 1, Probe) can produce an even higher charge density as a result of a small (e.g., 1-mm sphere) electrode area and is considered safe (American Academy of Neurology, 1990; Gordon et al., 1990). Charge density is also high without overt histologic neuronal damage in kindling experiments (see Table 1, Kindle) (Aird et al., 1984; Wada et al., 1978). Very brief cortical pulse train stimulation for MEP monitoring in humans (see Table 1, cMEP) was less than $12 \mu \mathrm{C} / \mathrm{cm}^{2} \times \mathrm{ph}$ but exceeded $6 \mu \mathrm{C} / \mathrm{ph}$ at maximum intensity and did not appear injurious clinically (Taniguchi et al., 1993a). All these methods involve brief ( $<5$ seconds) or very brief $(<0.03$ second) pulse trains producing total charge and total charge densities several orders of magnitude less than those of chronic stimulation models. The relevance of charge per phase discrepancies with such vastly different total charges is questionable. However, brief intermittent trains below injury thresholds in prolonged stimulation experiments should not damage neurons (Agnew and McCreery, 1987; Gordon et al., 1990; McCreery et al., 1990).

According to Wasserman (1998), TMS and repetitive TMS (rTMS) instrument manufacturers estimate a max- imum intracerebral charge density of $3 \mu \mathrm{C} / \mathrm{cm}^{2} \cdot \mathrm{ph}$. Histology in rats and epilepsy surgery patients exposed to TMS have not identified neuronal damage (Gates et al., 1992; Mano et al., 1988; Sgro et al., 1991). Single photon emission computed tomography shows regional cerebral blood flow increases resembling voluntary movement, but no adverse patterns with TMS or TES (Dressler et al., 1990). Magnetic resonance brain images show no changes after rTMS (Nahas et al., 2000). Neuronal damage from TMS or rTMS is considered to be highly unlikely (Wasserman, 1998).

Transcranial electrical stimulation produces relatively high scalp charge and density (see Table 1), but scalp shunting and skull dispersion pass only a diffused fraction to the brain (Nathan et al., 1992; Saypol et al., 1991). Levy et al. (1984) estimated cortical current density to be one-thirtieth of that under scalp electrodes during TES. Epidural TES amplitude measured through a burr hole was one-twentieth of that at the scalp. That this fell further above $50-\mathrm{Hz}$ stimulation was attributed to frequency-dependent capacitance effects of the scalp and skull. Thresholds for very brief pulse train muscle responses are substantially higher for TES (Calancie et al., 1998) than for direct cortical MEPs (Taniguchi et al., 
1993a). Although Agnew and McCreery (1987) used the 1:30 estimate by Levy et al. (1984), the cortical charge values listed in Table 1 are based on a more cautious dispersion factor of 1:20. Even with this, all charge densities should be less than $12 \mu \mathrm{C} / \mathrm{cm}^{2} \cdot \mathrm{ph}$, and total charge values should be five to seven orders of magnitude less than those of prolonged stimulation in animal experiments, and two to four orders of magnitude less than those of safe grid or probe cortical stimulation in humans. This makes brain damage resulting from even maximum-intensity TES MEPs exceedingly unlikely. Larger or multiple scalp electrodes to reduce charge density further appear unnecessary. At normal submaximal operating intensities, charge densities are likely to be comparable with TMS.

Estimated electroconvulsive therapy (ECT) cerebral current density can be less than $12 \mu \mathrm{C} / \mathrm{cm}^{2} \times$ ph with large scalp electrodes, but charge per phase remains relatively high (see Table 1). Total charge and total charge density are two to three orders of magnitude more than TES for MEP monitoring but are well below prolonged stimulation experiments. That even ECT is not thought to cause brain damage (Marangell et al., 1999) also makes neuronal injury unlikely during much less intense TES for MEP monitoring.

That current might concentrate through low-resistance paths such as the optic foramen, auditory canal, or skull defects (Agnew and McCreery, 1987) is not supported by reports of visual or auditory symptoms after TES. Convexity subdural air reduces TES effectiveness in sitting position posterior fossa surgeries (Kombos et al., 2000b, b), indicating that current does not concentrate through the suboccipital craniectomy to activate the brainstem. Digitimer Ltd. (2002) currently advises against TES with convexity skull fracture or craniotomy because of the possibility of high local current density. However, ECT has been administered safely with antecedent craniotomy (Krahn et al., 1993), and I have applied TES during prefrontal craniotomy for anterior communicating artery aneurysm without MEP change after opening and without clinical adverse effects (unpublished data). Transcranial electrical stimulation is not possible during craniotomy for central hemisphere surgery when direct cortical stimulation is indicated (Taniguchi et al., 1993a). Although TMS can be safe with implanted intracerebral electrodes (Kumar et al., 1999; Wasserman, 1998), there appears to be no TES experience with this or other devices such as cochlear implants. Digitimer Ltd. (2002) currently advises against TES with implanted biomedical devices or intracranial vascular clips.

There are no reports of clinical symptoms suggesting neuronal damage among thousands of patients who have undergone TES MEP monitoring. More analogous animal models and precise cortical charge density measurements would be of confirmatory interest.

\section{Seizures}

Electrical brain stimulation can provoke a sequence of abnormal neuronal discharges that may persist as afterdischarges sometimes progressing to a clinical seizure. Interacting factors include stimulus parameters, anesthesia, subject predisposition, and the chance of spontaneous seizures unrelated to stimulation.

Several brain stimulation methods use 50 to $60-\mathrm{Hz}$ pulse trains of $\geq 1$ second (see Table 1). Afterdischarges are routine during traditional cortical stimulation in awake or locally anesthetized humans predisposed by cortical lesions and/or epilepsy (Luciano et al., 1993). Although intensity is adjusted normally to less than afterdischarge thresholds, seizures occur in 5 to $20 \%$ and are sometimes sought for diagnostic purposes (Chauvel et al., 1993; Sartorius and Berger, 1998). Kindling and chronic stimulation experiments generate seizures readily in unanesthetized animals (Goddard et al., 1969; Pudenz et al., 1975; Wada and Sata, 1974; Wada et al., 1978; Yuen et al., 1981). Electroconvulsive therapy causes seizures in anesthetized unpredisposed subjects and generates high total scalp charge, which is the dosing parameter. Seizure thresholds range from 36 to $869 \times$ $10^{3} \mu \mathrm{C}$ (Sackeim et al., 1991) — two to three orders of magnitude above maximum TES for MEPs (see Table 1). Fifty to $60-\mathrm{Hz}$ trains of $\geq 1$ second are highly seizurogenic and, with sufficient intensity and duration, require neither an unanesthetized state nor a predisposition to generate seizures.

Three to $25-\mathrm{Hz}$ pulse trains of 0.75 to 10 seconds have provoked seizures in several unpredisposed awake subjects during rTMS, prompting the development of safety guidelines (Chen et al., 1997; Conca et al., 2000; Wasserman, 1998). For comparative purposes, stimulus parameters for one of these cases are listed under rTMS in Table 1. These stimulus characteristics are moderately seizurogenic in unpredisposed subjects but have not been studied under anesthesia.

In contrast, seizures are rare with low-frequency $(<0.5 \mathrm{~Hz})$ pulses or very brief $(<0.03$ second $)$ highfrequency pulse trains. The only published reports have involved single-pulse TMS in a few unanesthetized patients with predisposing brain lesions-a small fraction of many thousands of studies (Wasserman, 1998). At $150 \%$ MEP threshold, $1-\mathrm{Hz}$ rTMS of more than 50 seconds and $25-\mathrm{Hz}$ rTMS of as long as 0.24 second are 
TABLE 2. Published reports of low-frequency $(<0.5 \mathrm{~Hz})$ single-pulse and very brief $(<0.03$ second) high-frequency pulse train MEP monitoring

\begin{tabular}{|c|c|c|c|c|c|}
\hline \multicolumn{3}{|c|}{ Single-pulse } & \multicolumn{3}{|c|}{ Very brief pulse train } \\
\hline Author & $\mathrm{n}$ & Method & Author & $\mathrm{n}$ & Method \\
\hline de Noordhout (1996) & 19 & Direct & Cedzich (1996; 1998) & 74 & Direct \\
\hline Horikoshi (2000) & 50 & & Kawaguchi (1996) & 21 & \\
\hline \multirow[t]{2}{*}{ Katayama (1988) } & 20 & & Kombos (2000a; 2001) & 70 & \\
\hline & 89 & & Krombach (1998) & 26 & \\
\hline Andersson (1999) & 38 & TES & Taniguchi (1993a) & 9 & \\
\hline Boyd (1986) & 11 & & & 200 & \\
\hline Burke $(1992 ; 2000)$ & 130 & & Bartley (2002) & 100 & TES \\
\hline Gokaslan (1997) & 16 & & Calancie $(1998 ; 2001)$ & 561 & \\
\hline Hicks (1991) & 40 & & Deletis (2001a,b) & 14 & \\
\hline Jellinek (1991a,b) & 43 & & Jacobs $(1999 ; 2000)$ & 222 & \\
\hline Kalkman $(1991 ; 1992)$ & 22 & & Jones (1996) & 22 & \\
\hline Kothbauer (1997) & 87 & & Kakimoto (2000) & 115 & \\
\hline Lang (1996) & 40 & & Kawaguchi (2000) & 58 & \\
\hline Levy (1987) & 98 & & Kombos $(2000 b)$ & 8 & \\
\hline Morota (1997) & 32 & & Kothbauer $(1997 ; 1998)$ & 143 & \\
\hline Stephen (1996) & 160 & & MacDonald (2001; 2002) & 48 & \\
\hline Tabaraud (1993) & 27 & & Meylaerts (1999) & 38 & \\
\hline Thompson (1991) & 6 & & Pechstein $(1996 ; 1998)$ & 40 & \\
\hline Ubags (1996; 1999) & 25 & & Pelosi (2001) & 50 & \\
\hline Yang (1994) & 12 & & Rodi (1996) & 3 & \\
\hline \multirow[t]{2}{*}{ Zentner (1989a,b; 1991) } & 105 & & Ubags $(1997 ; 1998)$ & 22 & \\
\hline & 787 & & van Dongen (1999a,b,c,d; 2000) & 58 & \\
\hline Algio (2002) & 27 & TMS & Zhou (2000) & 12 & \\
\hline Firsching (1991) & 10 & & & $\overline{1,514}$ & \\
\hline Glassman (1995) & 18 & & & & \\
\hline Herdmann (1993) & 13 & & & & \\
\hline Kitagawa (1995) & 34 & & & & \\
\hline Lee (1995) & 8 & & & & \\
\hline Sihle-Wissel (2000) & 33 & & & & \\
\hline \multirow[t]{2}{*}{ Taniguchi (1993b) } & 77 & & & & \\
\hline & 325 & & & & \\
\hline & 1,201 & & & 1,714 & \\
\hline Grand total & 2,915 & & & & \\
\hline
\end{tabular}

Direct, direct cortical stimulation; TES, transcranial electric stimulation; TMS, transcranial magnetic stimulation; n, number of patients reported by each author in one or more studies. The only published adverse events are three instances of tongue biting (Jones et al., 1996; Kothbauer et al., 1998) and one mandibular fracture (Calancie et al., 2001) associated with pulse train TES.

considered safe in awake, unpredisposed subjects (Wassermann, 1998).

Table 2 lists 68 publications involving 2,915 anesthetized patients without seizures during low-frequency single-pulse $(n=1,201)$ or very brief high-frequency pulse train $(\mathrm{n}=1,714)$ MEP monitoring, including direct cortical stimulation in predisposed subjects $(n=289)$ (Aglio et al., 2002; Andersson and Ohlin, 1999; Bartley et al., 2002; Boyd et al., 1986; Burke et al., 1992, 2000; Calancie et al.,1998, 2001; Cedzich et al., 1996, 1998; Deletis et al., 2000a, b; de Noordhout et al., 1996; Firsching et al., 1991; Glassman et al., 1995; Gokaslan et al., 1997; Herdmann et al., 1993; Hicks et al., 1991; Horikoshi et al., 2000; Jacobs et al., 1999, 2000; Jellinek et al., 1991a, b; Jones et al., 1996; Kakimoto et al., 2000; Kalkman et al., 1991, 1992; Katayama et al., 1988;
Kawaguchi et al., 1996, 2000; Kitagawa et al., 1995; Kombos et al., 2000a, b, 2001; Kothbauer et al., 1997, 1998; Krombach et al., 1998; Lang et al., 1996; Lee et al., 1995; Levy, 1987; MacDonald, 2001; MacDonald and Janusz, 2002; Meylaerts et al., 1999; Morota et al., 1997; Pechstein, 1996, 1998; Pelosi et al., 2001; Rodi et al., 1996; Sihle-Wissel et al., 2000; Stephen et al., 1996; Tabaraud et al., 1993; Taniguchi et al., 1993a, b; Thompson et al., 1991; Ubags et al., 1996, 1997, 1998, 1999; van Donegen, 1999a-d, 2000; Yang et al., 1994; Zentner 1989, 1991; Zentner et al., 1989; Zhou and Zhu, 2000).

No pulse train TES seizures have been encountered in the unpublished experience of several investigators: Schwartz, n > 9,000; de Haan, $\mathrm{n}>700$; Pechstein, $\mathrm{n}>$ 100; Burke, $\mathrm{n}>50$; and Jones, $\mathrm{n}>30$ (personal communications). However, Digitimer Ltd. has identi- 
fied one unpublished seizure with the D185 in more than 10,000 documented cases. Deletis (personal communication) has encountered three unpublished seizures using a custom-made pulse train stimulator among 5,000 casesone related in time to stimulation and the other two not related. In more than 200 unpublished cases, I encountered one generalized seizure during skull base surgery under propofol and fentanyl anesthesia in a nonepileptic patient predisposed by an occipital ventriculoperitoneal shunt. It occurred 2 minutes after the last stimulation (Viking, 175-V, 500-Hz, five-pulse trains) on breaching dura near the temporal lobe, which could have induced the seizure. Transcranial electrical stimulation was stopped, phenytoin administered, and there were no further seizures.

There is currently no identifiable seizure risk with low-frequency single pulses under anesthesia, but based on the previous five events in more than 15,000 cases, pulse train TES has a rare but not negligible association with seizures. Spontaneous seizures may complicate intracranial surgeries (Ravussin and Wilder-Smith, 2001; Suri et al., 1998). Some anesthetics can exhibit proconvulsant properties during induction, surgery, or recovery, including cortical seizures with an EEG expression and subcortical seizurelike motor phenomena with no EEG correlate. Clinical proconvulsant effects have occurred with nitrous oxide, enflurane, etomidate, ketamine, propofol, morphine, meperidine, fentanyl, sufentanil, alfentanil, and local anesthetics; EEG seizures have occurred with enflurane, sevoflurane, etomidate, meperidine, and local anesthetics (Modica et al., 1990a, b; Woodforth et al., 1997; Yasukawa and Yasukawa, 1999). In epileptic patients, spike activation or seizure activity has occurred with enflurane, sevoflurane, methohexital, etomidate, benzodiazepines, ketamine, propofol, alfentanil, and remifentanil (Cascino et al., 1993; Komatsu et al., 1994; Modica et al., 1990a, b; Wass et al., 2001). Therefore, some seizurelike events could be coincidental unless EEG demonstrates TES-induced seizure patterns. Since afterdischarges can build up over seconds or minutes before symptomatic expression a clinical seizure that does not immediately follow stimulation could still be due to TES. Transcranial electrical stimulation should be discontinued in the rare event of clinical or EEG seizure activity unless shown to be unrelated to stimulation. Woodforth et al. (1997) applied single-pulse TES safely after a sevoflurane EEG seizure.

The convulsions of ECT can produce pulmonary, cardiac, and traumatic complications (Ali and Tidmarsh, 1997; Tecoult and Nathan, 2001). Intubation should prevent pulmonary complications, but intraoperative convulsions could cause serious morbidity. Fortunately, this has not occurred during the few observed events associated with TES.

Again, based on unpublished experience, the chance of seizures may be somewhat higher with direct, very brief pulse train stimulation during cortical lesion surgery under anesthesia. Among 50 brain tumor cases, Sala (personal communication) has encountered seizures in three, two with a history of seizures. In a subset of 138 cases, Cioni (personal communication) encountered one partial leg motor seizure using five-pulse train stimulation of the hand area in a brain tumor patient with epilepsy. The Bonn group (Neuloh and Schramm, personal communication) has encountered two seizures in more than 100 unpublished cases; one had preoperative seizures and precentral astrocytoma and the other had a frontal arteriovenous malformation. Considering these observations along with the 200 published cases without seizures (see Table 2), there appears to be a substantially lower chance of seizures in these patients than traditional 50 to $60-\mathrm{Hz}$, more than 1 -second cortical stimulation during local anesthesia. This is likely the result of both the different stimulus parameters and anesthesia. This method may represent an advance because MEP monitoring can be performed in addition to motor mapping under anesthesia with a lower chance of seizures, but may risk electrolytic neuronal toxicity resulting from direct monophasic stimuli. Based on these observations, a cortical lesion should be a relative TES contraindication that must be weighed against the level of motor deficit risk involved in the surgery to be monitored.

Epilepsy may predispose to transcranial stimulationprovoked seizures (Classen et al., 1995). However, studies of rTMS in epileptic patients do not support this idea, possibly because of anticonvulsant therapy (Wassermann, 1998), and there is even evidence for an anticonvulsive effect of rTMS (Ebert and Ziemann, 1999; Fleischmann et al., 1999). Although Digitimer Ltd. (2002) advises against TES with epilepsy, this is not always considered a contraindication (Burke, personal communication). When the risk of paraplegia was great, de Haan (personal communication) used TES in 21 epileptic patients without inducing seizures. Gugino and Schwartz (2001) stated that TES can be safe with epilepsy, but advised exclusion of patients with recent-onset seizures. Raised intracranial pressure or severe heart disease contraindicate ECT because of serious seizure complications (Marangell et al., 1999) and should be considered TES contraindications, but these patients should not be cleared for surgery. Tricyclic antidepressants and neuroleptics are possible cofactors in rTMSprovoked seizures (Wassermann, 1998) and may be considered as relative TES contraindications. Similarly, it 
may be reasonable to avoid particularly proconvulsant anesthetics such as etomidate or enflurane (Digitimer Ltd., 2002; Modica et al., 1990b). EEG monitoring can detect afterdischarges during rTMS (Boutros et al., 2000; Wasserman, 1998); however, in my view this should be optional for TES MEP monitoring because of the rare association with seizures. If used, the monitorist should be a competent interpreter prepared to differentiate TES seizures from anesthetic patterns or seizures.

\section{Kindling}

Kindling is an animal model consisting of progressive and persistent reductions of afterdischarge and seizure thresholds to periodic focal brain stimulation and sometimes the emergence of spontaneous seizures. One-second $60-\mathrm{Hz}$ rectangular or sine wave pulse trains at 1-day intervals appear to be optimal, and the amygdala is targeted because other cerebral structures are less susceptible (Goddard et al., 1969; Wada and Sata, 1974; Wada et al., 1978; Wasserman, 1998). Kindling is difficult in higher species and has not been demonstrated conclusively in humans (Wada et al., 1978; Wasserman, 1998).

Provoked seizures are not thought to produce subsequent epilepsy. Seizures resulting from traditional direct cortical stimulation are not believed to be epileptogenic, and seizures provoked by rTMS have not been followed by spontaneous seizures (Wassermann, 1998). The only human application resembling kindling is ECT, which induces convulsions with $60-\mathrm{Hz}$ pulse trains of more than 1 second every 2 to 3 days. Six to 12 administrations are given whereas an average of 196 daily stimulations are required to kindle rhesus monkeys (Marangell et al., 1999; Wada et al., 1978). Blackwood et al. (1980) found no difference from control subjects in the incidence of epilepsy after ECT. Devinsky and Duchowny (1983) found the incidence of spontaneous seizures after convulsive therapy to be five times higher than nonpsychiatric control subjects but concluded this was the result of individual predisposition. The stimulus parameters, target, and effects of TES MEP monitoring are very different than kindling experiments or ECT (see Table 1), and clinical experience involving thousands of patients has not identified an example resembling kindling.

\section{Epidural Complications}

Single-pulse TES MEPs involve spinal epidural electrodes inserted by the surgeon after opening or inserted percutaneously by an anesthesiologist (Burke and Hicks, 1998; Deletis, 1993). Radicular irritation and epidural hematoma or infection could cause serious morbidity.
Epidural catheterization for anesthesia is a common procedure, and epidural electrodes are also used for cord stimulation or sensory evoked potential monitoring (Halonen et al., 1990; Matsui et al., 1994; Schwartz et al., 1996; Wilson-Holden et al., 2000).

Neurologic complications of epidural catheterization for anesthesia are rare and mostly related to injected substance toxicity (Brown, 2000; Gieber et al., 1997; Kane, 1981). Radicular irritation usually resolves after catheter removal (Gieber et al., 1997). In a comprehensive review spanning 90 years, Vandermeulen et al. (1994) noted the incidence of epidural hematoma to be $1: 150,000$ and identified only 61 reported incidents, mostly associated with traumatic insertion or clotting disorders. With precautions, epidural catheterization is considered safe even with intraoperative anticoagulation (Brown, 2000; Vandermeulen et al., 1994).

Of the studies published in Table 2, 794 patients had epidural MEP recordings without complications, including 19 during heparinized thoracoabdominal aneurysm surgery (MacDonald and Janusz, 2002). Nor have there been any unpublished complications in two institutions with notable experience (Burke and Deletis, personal communication). Nevertheless, the possibility exists and requires consideration if paraplegia occurs after surgery monitored with epidural electrodes (Burke, personal communication).

Muscle MEP monitoring will reduce epidural recordings, particularly percutaneous electrode insertions (MacDonald and Janusz, 2002). However, the fluctuant nonlinear transfer of corticospinal volleys to motor units causes substantial trial-to-trial muscle response variability (Jones et al., 1996; Kothbauer et al., 1998). Consequently, there is no agreement on warning criteria, which have ranged from a more than $100-\mathrm{V}$ threshold increase (Calancie et al., 2001) to amplitude reductions less than $50 \%$ (Pelosi et al., 2001) or 25\% (Jacobs et al., 1999) of baseline, to disappearance (Kothbauer et al., 1998; MacDonald and Janusz, 2002). The greater stability of epidural MEPs facilitates quantitative monitoring (Bartley et al., 2002; Deletis, 1993). Applying both enhances intramedullary spinal cord surgery (Kothbauer et al., 1997, 1998) and possibly other spinal surgeries (Bartley et al., 2002). Consequently, there continue to be valid indications for epidural MEP despite this risk.

\section{Movement-Related Injury}

There is a chance of accidental injury if patient movement occurs when a surgical instrument is on a neural structure. The lack of muscle response to single-pulse TES (Burke and Hicks, 1998; Deletis, 1993) precludes 
such an injury. With pulse trains and incomplete neuromuscular blockade, there will be some induced or occasionally spontaneous movement. This is not dangerous during thoracoabdominal aneurysm or orthopedic surgery omitting neuromuscular blockade (MacDonald and Janusz, 2002; MacDonald et al., 2001). In my experience, these surgeons become accustomed to the intermittent patient twitch and do not find that this interferes with performing the surgery. There may be greater interference and risk during neurosurgery (Calancie et al., 1998, 2001; Kothbauer et al., 1998) although no injuries have been identified.

One preventive strategy is to adjust stimulus intensity to threshold (Calancie et al., 1998, 2001) or to minimal, or to no movement in the surgical field. There may be more movement when monitoring leg muscles that usually have higher thresholds than hand muscles (Calancie et al., 1998). C1/2 or C3/4 stimulus montages promote this strategy because of predominantly anode-contralateral limb movement (Calancie et al., 1998; Deletis et al., 2001a, b; MacDonald and Janusz, 2002). Left and then right MEPs are obtained with right and then left scalp anodal stimulation. Bilateral, stronger twitches may occur with a vertex anode-to-basal cathode array (Ubags et al., 1996).

Occasionally, careful timing of more intermittent stimuli becomes necessary, but reduces the rapidity of surgical feedback (Kothbauer et al., 1998). Monitoring the microscope image or other video of the surgical field assists stimulus timing (Calancie et al., 1998).

Another approach is to use higher intensity but dampen movement with controlled and monitored partial neuromuscular blockade (Lang et al., 1996; van Dongen et al., 1999c). This may reduce muscle MEP variability when relaxation is stable (Pelosi et al., 2001), but the added complexity is avoided by some investigators (Calancie et al., 1998, 2001; Deletis et al., 2001a, b; Jones et al., 1996; Kothbauer et al., 1998; MacDonald and Janusz, 2002).

A novel approach is to precede single-pulse TES by foot sole stimulation, priming tibialis anterior spinal motor neurons through the withdrawal reflex to respond to a single corticospinal volley. This spatial facilitation can limit movement to the legs (Andersson and Ohlin, 1999).

Transcranial magnetic stimulation and spinal cord stimulation myogenic MEP monitoring methods are also subject to this risk. Spontaneous patient movement is always a neurosurgical risk, and a higher level of vigilance is required when neuromuscular blockade is incomplete.

\section{Bite Injuries}

Jones et al. (1996) reported one bitten tongue as a result of jaw muscle contraction during D185 pulse train TES and advised bite blocks. Kothbauer et al. (1998) reported two bitten tongues using a custom-made stimulator and advised padded Guedel tube protection. They noted particularly strong temporalis muscle contraction with $\mathrm{C} 3 / 4$ stimulation resulting from direct muscular depolarization, which can also occur with single pulses. This may be a reason to favor C1/2 stimulation. Gugino and Schwartz (2001) noted five bitten tongues, one requiring surgical repair among 8,200 cases using the D185. Digitimer Ltd. has identified a total of 27 known incidents of tongue or lip laceration in more than 10,000 cases using the D185, distributes caution labels to its customers, and advises the use of soft bite blocks. Calancie et al. (2001) reported a unique mandibular fracture using C3/4 D185 stimulation in one patient without a bite block.

\section{Cognitive and Affective}

Confusion and memory loss after ECT usually last about 30 minutes, sometimes more (Marangell et al., 1999; Tecoult and Nathan, 2001). Prevailing psychiatric opinion holds that there are no permanent deficits attributable to modern ECT (Brodaty et al., 2001; Marangell et al., 1999). This makes adverse cognitive effects unlikely with the much less intense nonconvulsive stimuli of TES MEP monitoring.

There is a beneficial affective response to ECT in depression. Whether similar benefits occur with nonconvulsive rTMS is currently under investigation (Wasserman, 1998). A short-term trend to improved verbal recall or a decrease in logical memory after rTMS has been reported, and the long-term neuropsychologic effects of rTMS are under investigation (Wassermann, 1998). There are no lasting neuropsychologic alterations with single-pulse TMS (Bridgers, 1991), and although not studied formally, there are no reports of neuropsychologic symptoms after TES MEP monitoring.

\section{Other Adverse Effects}

Gugino and Schwartz (2001) discontinued pulse train TES in one unpublished case of premature ventricular contractions 1 minute after stimulation in a patient with a mild cardiac history. Digitimer Ltd. has recently distributed information indicating a total of five reversible cardiac arrhythmias including three sudden bradycardias without sequelae in more than 10,000 cases using the D185. It seems likely that these rare events were coin- 
cidental. Syncope has rarely occurred during TMS, but has not been attributed to brain stimulation (Wasserman, 1998). Arrhythmias resulting form hypothalamic stimulation or as an isolated expression of a seizure discharge are remote possibilities. Cardiac pacemakers are considered a relative contraindication to rTMS because of the possibility of magnetic field disruption of the control circuitry. According to Gugino and Schwartz (2001), TES can be performed safely with cardiac pacemakers; however, Digitimer Ltd. (2002) advises against TES for these patients.

Cioni (personal communication) encountered one unreported case of intraoperative awareness, which is the only instance of which I know. This is an anesthetic rather than a TES complication, but it may be relevant because intravenous anesthesia is currently favored for muscle MEP monitoring (Kawaguchi et al., 2000; Pechstein et al., 1996, 1998; Pelosi et al., 2001; Ubags et al., 1998; van Dongen et al., 2000). I am not aware of any evidence that awareness is more likely than with inhalational anesthesia. Similar considerations apply to cortical sensory evoked potential monitoring, which also benefits from intravenous anesthesia (MacDonald, 2001).

There are no published reports of scalp burns with TES using 9-mm cup, adhesive, or spiral needle electrodes. Larger electrodes to reduce scalp charge density appear unnecessary. However, de Haan (personal communication) encountered two unpublished second-degree scalp burns at a $\mathrm{Cz}$ anode among 845 cases. The scalp discomfort of TES is irrelevant under anesthesia. Headache attributed to scalp muscle contraction can follow rTMS (Wassermann, 1998), but there are no reports of headache resulting from TES MEP monitoring.

Transient disturbances of hormonal homeostasis after seizures or ECT and transient alterations of thyroidstimulating hormone, prolactin, and T-lymphocyte subsets after rTMS can occur (Marangell et al., 1999; Wassermann, 1998). Such effects have not been studied with TES MEP monitoring, but do not appear to have any harmful potential.

\section{CONCLUSIONS}

The specific motor assessment of TES MEP monitoring clearly benefits patients undergoing surgery jeopardizing motor function. Regarding safety concerns, comparative analysis indicates that brain damage and kindling are unlikely. Under anesthesia, seizures with less than $0.5-\mathrm{Hz}$ single pulses are currently unknown and very brief $(<0.03$ second $)$ high-frequency transcranial pulse trains appear to have a very low but not negligible association with seizures. It is unclear whether this is
TABLE 3. Summary of identified adverse events in more than 15,000 TES MEP monitoring cases

\begin{tabular}{lccr}
\hline \multicolumn{1}{c}{ Complication } & Published & Unpublished & Total \\
\hline Tongue or lip laceration & 3 & 26 & 29 \\
Mandibular fracture & 1 & 0 & 1 \\
Seizure & 0 & 5 & 5 \\
Cardiac arrhythmia & 0 & 5 & 5 \\
Scalp burn & 0 & 2 & 2 \\
Intraoperative awareness & 0 & 1 & 1 \\
\hline
\end{tabular}

This summary is based on literature review, unpublished clinical experience of several investigators, and information from Digitimer Ltd. (personal communication). Bite injuries may be preventable with soft bite blocks. Some of the seizures may have been spontaneous rather than stimulation induced. Cardiac arrhythmias and intraoperative awareness may be unrelated to transcranial electric stimulation. There have been remarkably few adverse events.

greater than the chance of spontaneous intraoperative seizures, but clear that seizures are very rare compared with other clinical brain stimulation methods, probably as a result of the very brief stimuli, anesthesia, and the general absence of predisposing factors. Expert EEG afterdischarge monitoring should be optional. Although possible, there have been no known complications from spinal epidural recording electrodes or accidental injuries resulting from TES-induced patient movement during neurosurgery. Preventive strategies for the latter include stimulus adjustment, careful timing, video monitoring, and possibly controlled partial relaxation or spatial facilitation. Soft bite blocks may prevent infrequent and rarely severe bite injuries. Rare cardiac irregularities may have been coincidental. Burns at scalp stimulating electrode sites appear to be very rare. No adverse neuropsychologic effects, headache, or homeostatic disturbances have been recognized, but formal studies are lacking. Comprehensive relative contraindications include epilepsy, cortical lesions, convexity skull defects, raised intracranial pressure, cardiac disease, proconvulsant medications or anesthetics, intracranial electrodes, vascular clips or shunts, and cardiac pacemakers or other implanted biomedical devices. Otherwise unexplained intraoperative seizures and possibly cardiac arrhythmias are indications to abort TES. Table 3 summarizes all adverse events identified in this review. Unless more frequently realized adverse effects begin to emerge, none of these risks should outweigh the benefits of this method when indicated and used with informed consent and appropriate precautions in expert hands.

\section{REFERENCES}

Aglio LS, Romero R, Desai S, Ramirez M, Gonzales AA, Gugino LD. The use of transcranial magnetic stimulation for monitoring de- 
scending spinal cord motor function. Clin Electroencephalogr 2002;33:30-41

Agnew WF, McCreery DB. Considerations for safety in the use of extracranial stimulation for motor evoked potentials. Neurosurgery 1987;20:143-7.

Aird RB, Masland RL, Woodbury DM. Neurobiologic substrates of epilepsy. In: Aird RB, Masland RL, Woodbury DM. The epilepsies: a critical review. New York: Raven Press, 1984:1-40.

Ali PB, Tidmarsh MD. Cardiac rupture during electroconvulsive therapy. Anaesthesia 1997;52:884-6.

American Academy of Neurology. Assessment: intraoperative neurophysiology. Report of the Therapeutics and Technology Assessment Subcommittee of the American Academy of Neurology. Neurology 1990;40:1644-6.

Andersson G, Ohlin A. Spatial facilitation of motor evoked responses in monitoring during spinal surgery. Clin Neurophysiol 1999;110: $720-4$.

Barker AT, Freeston IL, Jalinous R, Jarratt JA. Magnetic stimulation of the human brain and peripheral nervous system: an introduction and the results of an initial clinical evaluation. Neurosurgery 1987;20:100-9.

Bartley K, Woodforth IJ, Stephen JP, Burke D. Corticospinal volleys and compound muscle action potentials produced by repetitive transcranial stimulation during spinal surgery. Clin Neurophysiol 2002:113:78-90.

Ben-David B, Haller G, Taylor P. Anterior spinal fusion complicated by paraplegia. A case report of a false-negative somatosensoryevoked potential. Spine 1987;12:536-9.

Blackwood DH, Cull RE, Freeman CP, Evans JI, Mawdsley C. A study of the incidence of epilepsy following ECT. J Neurol Neurosurg Psychiatry 1980;43:1098-102.

Boutros NN, Berman RM, Hoffman R, Miano AP, Campbell D, Ilmoniemi R. Electroencephalogram and repetitive transcranial magnetic stimulation. Depress Anxiety 2000;12:166-9.

Boyd SG, Rothwell JC, Cowan JM, et al. A method of monitoring function in corticospinal pathways during scoliosis surgery with a note on motor conduction velocities. J Neurol Neurosurg Psychiatry 1986;49:251-7.

Bridgers SL. The safety of transcranial magnetic stimulation reconsidered: evidence regarding cognitive and other cerebral effects. Electroencephalogr Clin Neurophysiol Suppl 1991;43:170-9.

Brodaty H, Berle D, Hickie I, Mason C. "Side effects" of ECT are mainly depressive phenomena and are independent of age. $J$ Affect Disord 2001;66:237-45.

Brown DL. Spinal, epidural and caudal anesthesia. In: Miller RD, ed. Anesthesia. 5th ed. New York: Churchill Livingstone, 2000:1491519.

Burke D, Bartley K, Woodforth IJ, Yakoubi A, Stephen JP. The effects of a volatile anaesthetic on the excitability of human corticospinal axons. Brain 2000;123:992-1000.

Burke D, Hicks RG. Surgical monitoring of motor pathways. J Clin Neurophysiol 1998;15:194-205.

Burke D, Hicks R, Stephen J, Woodforth I, Crawford M. Assessment of corticospinal and somatosensory conduction simultaneously during scoliosis surgery. Electroencephalogr Clin Neurophysiol 1992;85:388-96

Calancie B, Harris W, Brindle GF, Green BA, Landy HJ. Thresholdlevel repetitive transcranial electrical stimulation for intraoperative monitoring of central motor conduction. J Neurosurg (Spine 1) 2001;95:161-8.

Calancie B, Harris W, Broton JG, Alexeeva N, Green BA. "Thresholdlevel" multipulse transcranial electrical stimulation of motor cortex for intraoperative monitoring of spinal motor tracts: description of method and comparison to somatosensory evoked potential monitoring. J Neurosurg 1998;88:457-70.

Cascino GD, So EL, Sharbrough FW, et al. Alfentanil-induced epileptiform activity in patients with partial epilepsy. $J$ Clin Neurophysiol 1993;10:520-5

Cedzich C, Pechstein U, Schramm J, Schafer S. Electrophysiological considerations regarding electrical stimulation of motor cortex and brain stem in humans. Neurosurgery 1998;42:527-32.

Cedzich C, Taniguchi M, Schafer S, Schramm J. Somatosensory evoked potential phase reversal and direct motor cortex stimulation during surgery in and around the central region. Neurosurgery 1996;38:962-70

Chauvel P, Landre E, Trottier S, et al. Electrical stimulation with intracerebral electrodes to evoke seizures. In: Devinsky O, Beric A, Dogali M, eds. Electrical and magnetic stimulation of the brain and spinal cord. New York: Raven Press, 1993:115-21.

Chen R, Gerloff C, Classen J, Wassermann EM, Hallett M, Cohen LG. Safety of different inter-train intervals for repetitive transcranial magnetic stimulation and recommendations for safe ranges of stimulation parameters. Electroencephalogr Clin Neurophysiol 1997; 105:415-21

Cioni B, Meglio M, Rossi GF. Intraoperative motor evoked potentials monitoring in spinal neurosurgery. Arch Ital Biol 1999;137:11526.

Classen J, Witte OW, Schlaug G, Seitz RJ, Holthausen H, Benecke R. Epileptic seizures triggered directly by focal transcranial magnetic stimulation. Electroencephalogr Clin Neurophysiol 1995;94:19_ 25

Conca A, Konig P, Hausmann A. Transcranial magnetic stimulation induces 'pseudoabsence seizure.' Acta Psychiatr Scand 2000;101: $246-8$.

Dawson EG, Sherman JE, Kanim LE, Nuwer MR. Spinal cord monitoring. Results of the Scoliosis Research Society and the European Spinal Deformity Society survey. Spine 1991;16(8 Suppl): S361-4.

de Haan P, Kalkman CJ, Jacobs MJ. Spinal cord monitoring with myogenic motor evoked potentials: early detection of spinal cord ischemia as an integral part of spinal cord protective strategies during thoracoabdominal aneurysm surgery. Semin Thorac Cardiovasc Surg 1998;10:19-24.

de Haan P, Kalkman CJ, Ubags LH, Jacobs MJ, Drummond JC. A comparison of the sensitivity of epidural and myogenic transcranial motor-evoked responses in the detection of acute spinal cord ischemia in the rabbit. Anesth Analg 1996;83:1022-7.

Delecrin J, Nguyen The Tich S, Passuti N, Pereon Y. Neurogenic mixed evoked potential monitoring during scoliosis surgery: retrospective analysis of 149 cases. Rev Chir Orthop Reparatrice Appar Mot 2000;86:46-53.

Deletis V. Intraoperative monitoring of the functional integrity of the motor pathways. In: Devinsky O, Beric A, Dogali M, eds. Electrical and magnetic stimulation of the brain and spinal cord. New York: Raven Press, 1993:201-14.

Deletis V, Isgum V, Amassian VE. Neurophysiological mechanisms underlying motor evoked potentials in anesthetized humans. Part 1. Recovery time of corticospinal tract direct waves elicited by pairs of transcranial electrical stimuli. Clin Neurophysiol 2001a; 112:438-44.

Deletis V, Rodi Z, Amassian VE. Neurophysiological mechanisms underlying motor evoked potentials in anesthetized humans. Part 2. Relationship between epidurally and muscle recorded MEPs in man. Clin Neurophysiol 2001b;112:445-52.

Deletis V, Sala F. The role of intraoperative neurophysiology in the protection or documentation of surgically induced injury to the spinal cord. Ann N Y Acad Sci 2001;939:137-44.

de Noordhout AM, Born JD, Hans P, Remacle JM, Delwaide PJ. Intraoperative localisation of the primary motor cortex using single electrical stimuli. J Neurol Neurosurg Psychiatry 1996;60:44244.

Devinski O, Duchowny MS. Seizures after convulsive therapy: a retrospective case survey. Neurology 1983;33:921-5.

Digitimer Ltd. Multipulse stimulator model D185 operator's manual. Welwyn Garden City, UK: Digitimer Ltd., 2002.

Dressler D, Voth E, Feldmann M, Benecke R. Safety aspects of transcranial brain stimulation in man tested by single photon emission-computed tomography. Neurosci Lett 1990;119:153-5. 
Ebert U, Ziemann U. Altered seizure susceptibility after high-frequency transcranial magnetic stimulation in rats. Neurosci Lett 1999;273:155-8

Firsching R, Heinen-Lauten M, Loeschke G. The effects of halothane and nitrous oxide on transcranial magnetic evoked potentials. Anasthesiol Intensivmed Notfallmed Schmerzther 1991; 26(7): 381-3.

Fleischmann A, Hirschmann S, Dolberg OT, Dannon PN, Grunhaus L. Chronic treatment with repetitive transcranial magnetic stimulation inhibits seizure induction by electroconvulsive shock in rats. Biol Psychiatry 1999;45:759-63.

Forbes HJ, Allen PW, Waller CS, et al. Spinal cord monitoring in scoliosis surgery. Experience with 1168 cases. J Bone Joint Surg Br 1991;73:487-91.

Gates JR, Dhuna A, Pascual-Leone A. Lack of pathological changes in human temporal lobe after transcranial magnetic stimulation. Epilepsia 1992;33:504-8.

Gieber RM, Scherer RU, Peters J. Incidence of neurologic complications related to thoracic epidural catheterization. Anesthesiology 1997;86:55-63.

Girvin JP. A review of basic aspects concerning chronic cerebral stimulation. In: Cooper IS, ed. Cerebellar stimulation in man. New York: Raven Press, 1978:1-12.

Glassman SD, Zhang YP, Shields CB, Johnson JR, Linden RD Transcranial magnetic motor-evoked potentials in scoliosis surgery. Orthopedics 1995;18:1017-23.

Goddard GV, McIntyre DC, Leech CK. A permanent change in brain function resulting from daily electrical stimulation. Exp Neurol $1969 ; 25: 195-330$

Gokaslan ZL, Samudrala S, Deletis V, Wildrick DM, Cooper PR Intraoperative monitoring of spinal cord function using motor evoked potentials via transcutaneous epidural electrode during anterior cervical spinal surgery. J Spinal Disord 1997;10:299303.

Gordon B, Lesser RP, Rance NE, et al. Parameters for direct cortical electrical stimulation in the human-histopathologic confirmation. Electroencephalogr Clin Neurophysiol 1990;75(5):371-7.

Gugino LD, Schwartz DM. Monitoring motor evoked potentials. Presented at the annual meeting of the Society for Neurosurgical Anesthesia and Critical Care. New Orleans, LA, USA. September 12, 2001. [Available through Digitimer Ltd.]

Halonen JP, Jones SJ, Edgar MA, Ransford AO. Multi-level recordings of spinal SEPs during scoliosis surgery. Electroencephalogr Clin Neurophysiol Suppl 1990;41:342-7.

Herdmann J, Lumenta CB, Huse KO. Magnetic stimulation for monitoring of motor pathways in spinal procedures. Spine 1993;18(5): $551-9$.

Hicks RG, Burke DJ, Stephen JP. Monitoring spinal cord function during scoliosis surgery with Cotrel-Dubousset instrumentation. Med J Aust 1991;154:82-6.

Horikoshi T, Omata T, Uchida M, Asari Y, Nukui H. Usefulness and pitfalls of intraoperative spinal motor evoked potential recording by direct cortical electrical stimulation. Acta Neurochir (Wien) 2000;142:257-62.

Jacobs MJ, Meylaerts SA, de Haan P, de Mol BA, Kalkman CJ. Assessment of spinal cord ischemia by means of evoked potential monitoring during thoracoabdominal aortic surgery. Semin Vasc Surg 2000;13:299-307.

Jacobs MJ, Meylaerts SA, de Haan P, de Mol BA, Kalkman CJ. Strategies to prevent neurologic deficit based on motor-evoked potentials in type I and II thoracoabdominal aortic aneurysm repair. J Vasc Surg 1999;29:48-57.

Jellinek D, Jewkes D, Symon L. Noninvasive intraoperative monitoring of motor evoked potentials under propofol anesthesia: effects of spinal surgery on the amplitude and latency of motor evoked potentials. Neurosurgery 1991a;29:551-7.

Jellinek D, Platt M, Jewkes D, Symon L. Effects of nitrous oxide on motor evoked potentials recorded from skeletal muscle in patients under total anesthesia with intravenously administered propofol. Neurosurgery 1991b;29:558-62.

Jones SJ, Harrison R, Koh KF, Mendoza N, Crockard HA. Motor evoked potential monitoring during spinal surgery: responses of distal limb muscles to transcranial cortical stimulation with pulse trains. Electroencephalogr Clin Neurophysiol 1996;100:375-83.

Kai Y, Owen JH, Allen BT, Dobras M, Davis C. Relationship between evoked potentials and clinical status in spinal cord ischemia. Spine 1994:19:1162-7.

Kakimoto M, Inoue S, Sakamoto T, Kawaguchi M, Kitaguchi K, Furuya H. Intraoperative motor evoked potential monitoring: a review of 115 cases. Masui 2000;49:240-4.

Kalkman CJ, Drummond JC, Kennelly NA, Patel PM, Partridge BL. Intraoperative monitoring of tibialis anterior muscle motor evoked responses to transcranial electrical stimulation during partial neuromuscular blockade. Anesth Analg 1992;75:584-9.

Kalkman CJ, Drummond JC, Ribberink AA. Low concentrations of isoflurane abolish motor evoked responses to transcranial electrical stimulation during nitrous oxide/opioid anesthesia in humans. Anesth Analg 1991;73:410-5.

Kane RE. Neurologic deficits following epidural or spinal anesthesia. Anesth Analg 1981;60:150-61.

Katayama A, Tsubokawa T, Maejima S, et al. Corticospinal direct response in humans: identification of the motor cortex during intracranial surgery under general anesthesia. J Neurol Neurosurg Psychiatry 1988;51:50-9.

Kawaguchi M, Sakamoto T, Inoue S, et al. Low dose propofol as a supplement to ketamine-based anesthesia during intraoperative monitoring of motor-evoked potentials. Spine 2000;25:974-9.

Kawaguchi M, Sakamoto T, Ohnishi H, Shimizu K, Karasawa J, Furuya $\mathrm{H}$. Intraoperative myogenic motor evoked potentials induced by direct electrical stimulation of the exposed motor cortex under isoflurane and sevoflurane. Anesth Analg 1996;82:593-9.

Kitagawa H, Nakamura H, Kawaguchi Y, et al. Magnetic-evoked compound muscle action potential neuromonitoring in spine surgery. Spine 1995;20:2233-9.

Komatsu H, Taie S, Endo S, et al. Electrical seizures during sevoflurane anesthesia in two pediatric patients with epilepsy. Anesthesiology 1994;81:1535-7.

Kombos T, Suess O, Ciklatekerlio O, Brock M. Monitoring of intraoperative motor evoked potentials to increase the safety of surgery in and around the motor cortex. J Neurosurg 2001;95:608-14.

Kombos T, Suess O, Funk T, Kern BC, Brock M. Intra-operative mapping of the motor cortex during surgery in and around the motor cortex. Acta Neurochir (Wien) 2000a;142:263-8.

Kombos T, Suess O, Pietila T, Brock M. Subdural air limits the elicitation of compound muscle action potentials by high-frequency transcranial electrical stimulation. Br J Neurosurg 2000b; $14: 240-3$.

Kothbauer KF, Deletis V, Epstein FJ. Motor-evoked potential monitoring for intramedullary spinal cord tumor surgery: correlation of clinical and neurophysiological data in a series of 100 consecutive procedures. Neurosurg Focus 1998;4:

Kothbauer K, Deletis V, Epstein FJ. Intraoperative spinal cord monitoring for intramedullary surgery: an essential adjunct. Pediatr Neurosurg 1997;26:247-54

Krahn LE, Rummans TA, Peterson GC, Cascino GD, Sharbrough FW. Electroconvulsive therapy for depression after temporal lobectomy for epilepsy. Convuls Ther 1993;9:217-9.

Krombach GA, Spetzger U, Rohde V, Gilsbach JM. Intraoperative localization of functional regions in the sensorimotor cortex by neuronavigation and cortical mapping. Comput Aided Surg 1998; $3: 64-73$

Kumar R, Chen R, Ashby P. Safety of transcranial magnetic stimulation in patients with implanted deep brain stimulators. Mov Disord 1999; 14:157-8.

Lang EW, Beutler AS, Chesnut RM, et al. Myogenic motor-evoked potential monitoring using partial neuromuscular blockade in surgery of the spine. Spine 1996;21:1676-86. 
Lee WY, Hou WY, Yang LH, Lin SM. Intraoperative monitoring of motor function by magnetic motor evoked potentials. Neurosurgery 1995;36:493-500.

Leppanen R, Madigan R, Sears C, Maguire J, Wallace S, Captain J. Intraoperative collision studies demonstrate descending spinal cord stimulated evoked potentials and ascending somatosensory evoked potentials are mediated through common pathways. J Clin Neurophysiol 1999;16:170. Abstract.

Lesser RP, Raudzens P, Luders H, et al. Postoperative neurological deficits may occur despite unchanged intraoperative somatosensory evoked potentials. Ann Neurol 1986;19:22-5.

Levy WJ. Clinical experience with motor and cerebellar evoked potential monitoring. Neurosurgery 1987;20:169-82.

Levy WJ, York DH, McCaffrey M, Tanzer F. Motor evoked potentials from transcranial stimulation of the motor cortex in humans. Neurosurgery 1984;15:287-302.

Luciano D, Devinsky O, Pannizzo F. Electrocorticography during cortical stimulation. In: Devinsky O, Beric A, Dogali M, eds. Electrical and magnetic stimulation of the brain and spinal cord. New York: Raven Press, 1993:87-102.

MacDonald DB. Individually optimizing posterior tibial somatosensory evoked potential P37 scalp derivations for intraoperative monitoring. J Clin Neurophysiol 2001;18:364-71.

MacDonald DB, Al-Zayed Z, Dvorak M, et al. Spinal cord monitoring during scoliosis surgery utilizing multiple pulse transcranial electric stimulation motor evoked potentials and somatosensory evoked potentials. Clin Neurophysiol 2001;112(Suppl 1):S100-1.

MacDonald DB, Janusz M. An approach to intraoperative monitoring of thoracoabdominal aneurysm surgery. J Clin Neurophysiol 2002;19:43-54.

Mano Y, Yamamoto T, Miyauchi S, et al. The safety of magnetic stimulation. In: Wallinga W, Boom HBK, De Vries J, eds. Electrophysiological kinesiology. Amsterdam: Elsevier, 1988:191-4.

Marangell LB, Silver JM, Yudofsky SC. Psychopharmacology and electroconvulsive therapy. In: Hales RE, Yudofsky SC, Talbot JA, eds. The American Psychiatric Press textbook of psychiatry. 3rd ed. : American Psychiatric Press, 1999:1025-129.

Matsui Y, Goh K, Shiiya N, et al. Clinical application of evoked spinal cord potentials elicited by direct stimulation of the cord during temporary occlusion of the thoracic aorta. $J$ Thorac Cardiovasc Surg 1994;107:1519-27.

McCreery DB, Agnew WF, Yuen TG, Bullara LA. Charge density and charge per phase as cofactors in neural injury induced by electrical stimulation. IEEE Trans Biomed Eng 1990;37:996-1001.

McCreery DB, Agnew WF, Yuen TG, Bullara LA. Comparison of neural damage induced by electrical stimulation with faradaic and capacitor electrodes. Ann Biomed Eng 1988;16:463-81.

Merton PA and Morton HB. Stimulation of the cerebral cortex in the intact human subject. Nature 1980;285:227.

Meylaerts SA, Jacobs MJ, van Iterson V, De Haan P, Kalkman CJ. Comparison of transcranial motor evoked potentials and somatosensory evoked potentials during thoracoabdominal aortic aneurysm repair. Ann Surg 1999;230:742-9.

Minahan RE, Sepkuty JP, Lesser RP, Sponseller PD, Kostuik JP Anterior spinal cord injury with preserved neurogenic 'motor' evoked potentials. Clin Neurophysiol 2001;112:1442-50.

Modica PA, Tempelhoff R, White PF. Pro- and anticonvulsant effects of anesthetics (part I). Anesth Analg 1990a;70:303-15.

Modica PA, Tempelhoff R, White PF. Pro- and anticonvulsant effects of anesthetics (part II). Anesth Analg 1990b;70:433-44.

Morota N, Deletis V, Constantini S, Kofler M, Cohen H, Epstein FJ. The role of motor evoked potentials during surgery for intramedullary spinal cord tumors. Neurosurgery 1997;41:1327-36.

Nahas Z, DeBrux C, Chandler V, et al. Lack of significant changes on magnetic resonance scans before and after 2 weeks of daily left prefrontal repetitive transcranial magnetic stimulation for depression. J ECT 2000;16:380-90.

Nathan SS, Sinha SR, Gordon B, Lesser RP, Thakor NV. Determination of current density distributions generated by electrical stim- ulation of the human cerebral cortex. Electroencephalogr Clin Neurophysiol 1993;86:183-92.

Nuwer MR, Dawson EG, Carlson LG, Kanim LE, Sherman JE. Somatosensory evoked potential spinal cord monitoring reduces neurologic deficits after scoliosis surgery: results of a large multicenter survey. Electroencephalogr Clin Neurophysiol 1995;96: $6-11$.

Owen JH, Laschinger J, Bridwell K, et al. Sensitivity and specificity of somatosensory and neurogenic-motor evoked potentials in animals and humans. Spine 1988;13:1111-8.

Pechstein U, Cedzich C, Nadstawek J, Schramm J. Transcranial highfrequency repetitive electrical stimulation for recording myogenic motor evoked potentials with the patient under general anesthesia. Neurosurgery 1996;39:335-43.

Pechstein U, Nadstawek J, Zentner J, Schramm J. Isoflurane plus nitrous oxide versus propofol for recording of motor evoked potentials after high frequency repetitive electrical stimulation. Electroencephalogr Clin Neurophysiol 1998;108:175-81.

Pelosi L, Stevenson M, Hobbs GJ, Jardine A, Webb JK. Intraoperative motor evoked potentials to transcranial electrical stimulation during two anaesthetic regimens. Clin Neurophysiol 2001;112:107687.

Pudenz RH, Agnew WF, Bullara LA. Effects of electrical stimulation of brain. Brain Behav Evol 1977;14:103-25.

Pudenz RH, Bullara LA, Jacques S, Hambrecht FT. Electrical stimulation of the brain. III. The neural damage model. Surg Neurol 1975;4:389-400.

Ravussin P, Wilder-Smith O. General anaesthesia for supratentorial neurosurgery. CNS Drugs 2001;15:527-35.

Rodi Z, Deletis V, Morota N, Vodusek DB. Motor evoked potentials during brain surgery. Pflüger's Arch 1996;431(6 Suppl 2): R291-2.

Rose RD. Sensory component of cervically evoked motor potentials. Med Hypotheses 1996:46:577-9.

Sackeim HA, Devanand DP, Prudic J. Stimulus intensity, seizure threshold, and seizure duration: impact on the efficacy and safety of electroconvulsive therapy. Psychiatry Clin North Am 1991;14: 803-43.

Sala F, Niimi Y, Berenstein A, Deletis V. Neuroprotective role of neurophysiological monitoring during endovascular procedures in the spinal cord. Ann N Y Acad Sci 2001;939:126-36.

Sartorius CJ, Berger MS. Rapid termination of intraoperative stimulation-evoked seizures with application of cold Ringer's lactate to the cortex. Technical note. J Neurosurg 1998;88:349-51.

Saypol JM, Roth BJ, Cohen LG, Hallett M. A theoretical comparison of electric and magnetic stimulation of the brain. Ann Biomed Eng 1991:19:317-28.

Schwartz DM, Drummond DS, Ecker ML. Influence of rigid spinal instrumentation on the neurogenic motor evoked potential. J Spinal Disord 1996;9:439-45.

Sgro JA, Ghatak NR, Stanton PC, et al. Repetitive high magnetic field stimulation: the effect upon rat brain. Electroencephalogr Clin Neurophysiol 1991;43(Suppl):180-95.

Sihle-Wissel M, Scholz M, Cunitz G. Transcranial magnetic-evoked potentials under total intravenous anaesthesia and nitrous oxide. Br J Anaesth 2000;85:465-7.

Stephen JP, Sullivan MR, Hicks RG, Burke DJ, Woodforth IJ, Crawford MR. Cotrel-Dubousset instrumentation in children using simultaneous motor and somatosensory evoked potential monitoring. Spine 1996;21:2450-7.

Stephens SM, Greenberg RM, Pettinati HM. Choosing an electroconvulsive therapy device. Psychiatry Clin North Am 1991;14:9891006.

Su CF, Haghighi SS, Oro JJ, Gaines RW. "Backfiring" in spinal cord monitoring. Spine 1992;17:504-8.

Suri A, Mahapatra AK, Bithal P. Seizures following posterior fossa surgery. Br J Neurosurg 1998;12:41-4.

Tabaraud F, Boulesteix JM, Moulies D, et al. Monitoring of the motor pathway during spinal surgery. Spine 1993;18:546-50. 
Taniguchi M, Cedzich C, Schramm J. Modification of cortical stimulation for motor evoked potentials under general anesthesia: technical description. Neurosurgery 1993a;32:219-26.

Taniguchi M, Nadstawek J, Langenbach U, Bremer F, Schramm J. Effects of four intravenous anesthetic agents on motor evoked potentials elicited by magnetic transcranial stimulation. Neurosurgery $1993 b ; 33: 407-15$.

Tecoult E, Nathan N. Morbidity in electroconvulsive therapy. Eur $J$ Anaesthesiol 2001;18:511-8.

Thompson PD, Day BL, Crockard HA, et al. Intra-operative recording of motor tract potentials at the cervico-medullary junction following scalp electrical and magnetic stimulation of the motor cortex. J Neurol Neurosurg Psychiatry 1991;54:618-23.

Toleikis JR, Skelly JP, Carlvin AO, Burkus JK. Spinally elicited peripheral nerve responses are sensory rather than motor. Clin Neurophysiol 2000;111:736-42.

Ubags LH, Kalkman CJ, Been HD. Influence of isoflurane on myogenic motor evoked potentials to single and multiple transcranial stimuli during nitrous oxide/opioid anesthesia. Neurosurgery 1998;43:90-4.

Ubags LH, Kalkman CJ, Been HD, Drummond JC. Differential effects of nitrous oxide and propofol on myogenic transcranial motor evoked responses during sufentanil anaesthesia. $\mathrm{Br} \mathrm{J}$ Anaesth 1997;79:590-4.

Ubags LH, Kalkman CJ, Been HD, Drummond JC. The use of a circumferential cathode improves amplitude of intraoperative electrical transcranial myogenic motor evoked responses. Anesth Analg 1996;82:1011-4.

Ubags LH, Kalkman CJ, Been HD, Koelman JH, Ongerboer de Visser BW. A comparison of myogenic motor evoked responses to electrical and magnetic transcranial stimulation during nitrous oxide/opioid anesthesia. Anesth Analg 1999;88:568-72.

Vandermeulen EP, van Aken H, Vermylen J. Anticoagulants and spinal-epidural anesthesia. Anesth Analg 1994;79:1165-77.

van Dongen EP, ter Beek HT, Aarts LP, et al. The effect of two low-dose propofol infusions on the relationship between six-pulse transcranial electrical stimulation and the evoked lower extremity muscle response. Acta Anaesthesiol Scand 2000;44:799-803.

van Dongen EP, ter Beek HT, Schepens MA, et al. Effect of nitrous oxide on myogenic motor potentials evoked by a six pulse train of transcranial electrical stimuli: a possible monitor for aortic surgery. Br J Anaesth 1999a;82:323-8.

van Dongen EP, ter Beek HT, Schepens MA, et al. The relationship between evoked potentials and measurements of S-100 protein in cerebrospinal fluid during and after thoracoabdominal aortic aneurysm surgery. J Vasc Surg 1999b;30:293-300.

van Dongen EP, ter Beek HT, Schepens MA, et al. Within-patient variability of myogenic motor-evoked potentials to multipulse transcranial electrical stimulation during two levels of partial neuromuscular blockade in aortic surgery. Anesth Analg 1999c; $88: 22-7$. van Dongen EP, ter Beek HT, Schepens MA, et al. The influence of nitrous oxide to supplement fentanyl/low-dose propofol anesthesia on transcranial myogenic motor-evoked potentials during thoracic aortic surgery. J Cardiothorac Vasc Anesth 1999d;13:30-4.

Wada JA, Mizoguchi T, Osawa T. Secondarily generalized convulsive seizures induced by daily amygdaloid stimulation in rhesus monkey. Neurology 1978;28:1026-36.

Wada JA, Sata M. Generalized convulsive seizures induced by daily electrical stimulation of the amygdala in cats. Neurology 1974; $565-74$.

Wass CT, Grady RE, Fessler AJ, et al. The effects of remifentanil on epileptiform discharges during intraoperative electrocorticography in patients undergoing epilepsy surgery. Epilepsia 2001; 42:1340-4.

Wassermann EM. Risk and safety of repetitive transcranial magnetic stimulation: report and suggested guidelines from the International Workshop on the Safety of Repetitive Transcranial Magnetic Stimulation, June 5-7, 1996. Electroencephalogr Clin Neurophysiol 1998;108:1-16.

Wilson-Holden TJ, Padberg AM, Parkinson JD, Bridwell KH, Lenke LG, Bassett GS. A prospective comparison of neurogenic mixed evoked potential stimulation methods: utility of epidural elicitation during posterior spinal surgery. Spine 2000;25:2364-71.

Woodforth IJ, Hicks RG, Crawford MR, Stephen JP, Burke DJ. Electroencephalographic evidence of seizure activity under deep sevoflurane anesthesia in a nonepileptic patient. Anesthesiology $1997 ; 87: 1579-82$

Yang LH, Lin SM, Lee WY, Liu CC. Intraoperative transcranial electrical motor evoked potential monitoring during spinal surgery under intravenous ketamine or etomidate anaesthesia. Acta Neurochir (Wien) 1994;127:191-8.

Yasukawa M, Yasukawa K. Convulsion in two non-epileptic patients following induction of anesthesia with propofol. Masui 1999;48: 271-4.

Yuen TGH, Agnew WF, Bullara BS, et al. Histologic evaluation of neural damage from electrical stimulation: considerations for the selection of parameters for clinical application. Neurosurgery 1981;9(3):292-299.

Zentner J. Motor evoked potential monitoring during neurosurgical operations on the spinal cord. Neurosurg Rev 1991;14:29-36.

Zentner J. Noninvasive motor evoked potential monitoring during neurosurgical operations on the spinal cord. Neurosurgery 1989; 24:709-12.

Zentner J, Kiss I, Ebner A. Influence of anesthetics-nitrous oxide in particular-on electromyographic response evoked by transcranial electrical stimulation of the cortex. Neurosurgery 1989;24: $253-6$.

Zhou HH, Zhu C. Comparison of isoflurane effects on motor evoked potential and F wave. Anesthesiology 2000;93:32-8. 